\title{
Cooperative Teaching Exploring a Multidisciplinary Engineering Problem
}

\author{
José Couto Marques, Teresa Restivo, Pedro Portela, Ricardo Teixeira \\ Faculdade de Engenharia, Universidade do Porto \\ Rua Dr. Roberto Frias, 4200-465 Porto, Portugal
}

\begin{abstract}
The simple case study presented constitutes an illustrative example of how surprisingly rich an open-ended experimental problem may prove to be. This has involved an instrumented soft drink can and a PC as the starting point for a fruitful multidisciplinary investigation that ended up bringing together manpower and know-how from various engineering areas in a very rewarding cooperative teaching and learning exercise.
\end{abstract}

\section{Introduction}

The increasing specialisation of modern engineering curricula may contribute to an excessive fragmentation of teaching subjects, which hinders the formation of a global picture in the student's mind.

In the course of their basic experimental training, engineering students are, very routinely, supposed to achieve confirmatory results of simple physical laws or effects. The current availability of icon-based user-friendly graphical software for monitoring, control, data acquisition and interpretation, has provided students with an excellent training facility, which is intuitive, open, interactive and flexible ${ }^{1}$. In our opinion the exploration of this kind of tool in experimental engineering education can foster student creativity, turning passive observers into active participants and promoting a deeper understanding of the underlying physical and mathematical concepts, in line with Kolb's theory of experiential learning ${ }^{2}$.

We strongly believe that the use of carefully selected interdisciplinary problems has an extremely important role to play in helping to integrate knowledge from distinct engineering fields, with the added benefit of providing excellent opportunities for a cooperative learning/teaching/research practice, which can be highly motivating, creative and stimulating for both students and teachers.

\section{The starting point $-\mathbf{a}$ familiar object}

"Instrumentation for Measurement" is a $3^{\text {rd }}$ year, $2^{\text {nd }}$ semester, discipline of the 5 -year degree course in Mechanical Engineering, run at FEUP under the responsibility of the second author (TR), in which around $60 \%$ of the time is devoted to "hands on" laboratory activity involving over 140 students. In order to comply with the demands for a non-conventional final project topic coming from a highly dynamic group of students led by the third author (PP), an open experimental problem was devised (by TR) using a very familiar object - a beverage can. 
The students' assignment involved:

(i) Getting one can and carefully measuring its dimensions.

(ii) Instrumenting a similar can with strain gauges aligned in the axial and hoop directions and with a temperature sensor.

(iii) Estimating the strains magnitude by applying well-known formulas from engineering mechanics for an infinitely long thin-walled circular cylinder of isotropic elastic material with closed ends ${ }^{3}$, considering an applied internal pressure around $50 \mathrm{psi}$ $(0.345 \mathrm{MPa})^{4}$.

(iv) Using a data acquisition system to digitally record the can lid opening.

(v) Processing the gathered data in order to evaluate the duration of the corresponding transient stage.

(vi) Determining the strain increments and calculating the corresponding internal can pressure.

(vii) Checking the consistency of the estimated, measured and/or calculated values for strains and internal pressure.

The students would be granted bonus points if the range of strain values to be measured was adequately estimated beforehand, together with the corresponding data acquisition sampling rate, since these were important requisites for getting the experiment first time right.

This humble test probe has already received the attention of several authors ${ }^{4-7}$ and, as we shall see, it has indeed a lot to offer.

\section{A preliminary step - determination of material parameters}

With the generous help of our metallurgy experts the material parameters of the beverage can were identified, namely using emission spectroscopy analysis. The lid material is an aluminium alloy, while a steel alloy has been used for the can body. A test specimen from the can body was prepared for a tensile loading test (Figure 1) whose results are included in Table 1.

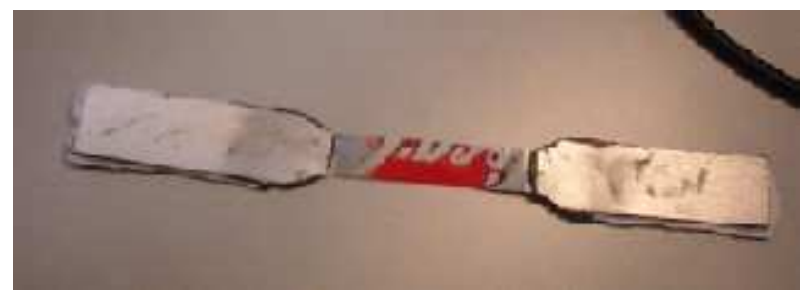

Figure 1-Can body specimen

Table 1 - Material parameters

\begin{tabular}{|c|c|c|c|}
\hline Can component & Material identification & Young modulus, $E(\mathrm{GPa})$ & Yield stress, $\sigma_{Y}(\mathrm{MPa})$ \\
\hline Top lid & Aluminium 5052 (AA) & 70 & 240 \\
\hline Body & Steel C2D1 (EN10016-3) & 205 & 455 \\
\hline
\end{tabular}




\section{The first step - the experimental results}

The can has been instrumented with one bonded strain gauge rosette (MM gauge type EA-06125RA-120) for strain variation measurement and with a K type thermocouple (connected to a digital multimeter with cold junction compensation) for temperature monitoring (see Figure 2). Two elements of the strain gauge rosette, oriented in the principal strain directions, are inserted in two distinct bridge circuits (Modular RDP 600 System - module type 628), using the three leading wire technique. Each conditioning circuit is prepared for $1 / 4$ bridge configuration using strain gauges of $120 \Omega$ nominal resistance. Two digital voltmeters (Keithley 2000) are used for initial quantification tests and adjustments of each bridge circuits. The data acquisition system comprises a PC with a software package from LabTech and a DAS PCL-818HG card with programmable gain. The A/D conversion resolution depends on the gain selected, which was defined taking into account the estimated magnitude of the strain decrement. The sampling rate for data acquisition was adjusted for the expected duration of the transient caused by the can opening (Figure 3).

\begin{tabular}{|c|c|c|c|}
\hline Instrumented can & $\begin{array}{c}\text { Conditioning } \\
\text { circuit } \\
\text { Modular RDP 6000 }\end{array}$ & $\begin{array}{c}\text { Data acquisition } \\
\text { terminals }\end{array}$ & $\begin{array}{c}\text { Application } \\
\text { developed using } \\
\text { LabTech }\end{array}$ \\
\hline & & & \\
\hline
\end{tabular}

Figure 2 - The instrumented can and the measurement system

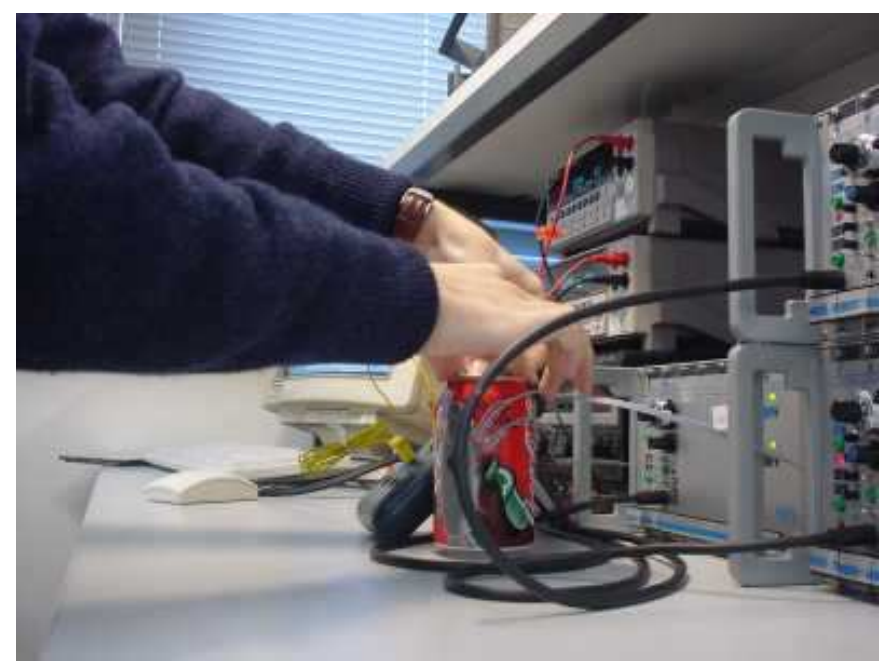

Figure 3 - Popping the can open

The results obtained were later processed and are listed below. 
Table 2 - Experimental results

\begin{tabular}{|l|c|}
\hline Can temperature & $17.1^{\circ} \mathrm{C}$ \\
\hline Duration of the transient associated to the can opening & $70 \mathrm{~ms}$ \\
\hline Longitudinal strain, $\varepsilon_{\mathrm{z}}$ & $-114 \mu \varepsilon$ \\
\hline Hoop strain, $\varepsilon_{\theta}$ & $-500 \mu \varepsilon$ \\
\hline
\end{tabular}

\section{The second step - checking the experimental results}

Isotropic elasticity and the long thin-walled circular cylinder simplifying model were the basic assumptions for checking the consistency of the results.

Using the values for $\varepsilon_{\theta}$ and $\varepsilon_{z}$ from Table 2, a Poisson ratio $v$ of 0.307 was found from

$$
\nu=\left(\varepsilon_{\theta^{-}}-2 \varepsilon_{z}\right) /\left(2 \varepsilon_{\theta^{-}} \varepsilon_{z}\right)
$$

The internal pressure $p$ was determined from the hoop strain $\varepsilon_{\theta}$ (a strategy less sensitive to errors in Poisson ratio than using the longitudinal strain $\varepsilon_{z}{ }^{4}$ ) as

$$
p=2 t E \varepsilon_{\theta} /[r(2-v)]
$$

where $t$ and $r$ are respectively the can wall thickness $(0.11 \mathrm{~mm})$ and radius $(33 \mathrm{~mm})$ at mid height, which led to a value for $p$ of $0.404 \mathrm{MPa}$ (58.54 psi).

The corresponding hoop and longitudinal stresses $\sigma_{\theta}$ and $\sigma_{z}$ are given by

$$
\begin{aligned}
& \sigma_{\theta}=p r / t \\
& \sigma_{z}=p r /(2 t)
\end{aligned}
$$

and are found to be $121.09 \mathrm{MPa}(17561.5 \mathrm{psi})$ and $60.54 \mathrm{MPa}(8780.8 \mathrm{psi})$, respectively.

Finally the generalized Hooke's law led to $-113.56 \mu \varepsilon$ and $-497.57 \mu \varepsilon$ respectively for the longitudinal and hoop strains, which are in superb agreement with the measured values of Table 2. On the other hand, the computed internal pressure of $0.404 \mathrm{MPa}$ (or $58.54 \mathrm{psi}$ ) is slightly above the expected reference value of $50 \mathrm{psi}(0.345 \mathrm{MPa})$.

\section{The third step - the numerical modelling - linear finite element analysis}

In order to investigate more thoroughly the structural response of the can and as a complement to the experimental work, the decision was taken to explore the problem further by performing a numerical study, with the help of the first and fourth authors (JCM and RT).

Using the available geometrical and material data a two dimensional axisymmetric 8-noded isoparametric finite element mesh was set up ${ }^{8}$, with a total of 340 elements and 1684 nodes. The mesh is depicted in Figure 4, which includes enlarged views of the top and base zones of the can mesh. A purely linear elastic small strain analysis was first carried out, applying the previously encountered internal pressure value of $0.404 \mathrm{MPa}$ (58.54 psi). The corresponding hoop and longitudinal stress distribution at mid-height is shown in Figure 4 and can be seen to agree perfectly well with the values reported above. This seems to validate, on one hand, 
the adoption of the long thin-walled circular cylinder formulas for stress estimation and, on the other hand, it indicates that the effect on the stress field of the lid and base cross section geometry is confined to the can extremities, at least for such low pressure level.
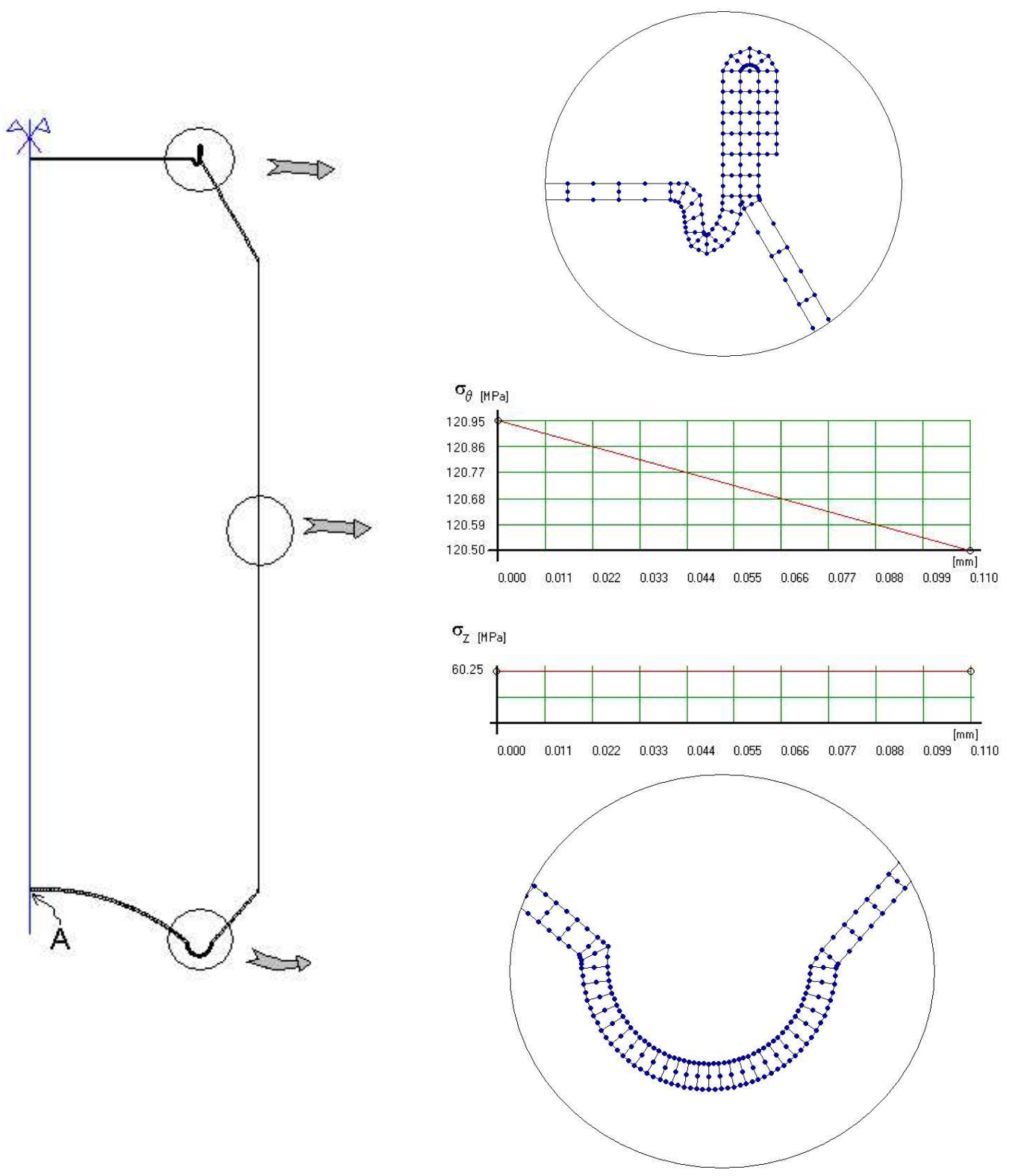

Figure 4 - Finite element mesh and stress distribution obtained with a linear analysis

\section{The fourth step - numerical modelling continued - geometrically non-linear analysis}

Encouraged by these preliminary results we then decided to investigate the can behaviour in the large deformation range, including base dome reversal. A geometrically non-linear analysis was performed ${ }^{9}$, using the arc-length method to steer the applied internal pressure past limit points. Material non-linearity was not considered at this stage, so as to better assess the contribution of each type of non-linearity to the can response. Figure 5 illustrates the 
evolution of the can geometry, while Figure 6 shows the pressure - vertical displacement curve for point $\mathrm{A}$ of the base dome (see Figure 4). The pressure required for initiating the dome reversal process was $8.86 \mathrm{MPa}(1285 \mathrm{psi})$.

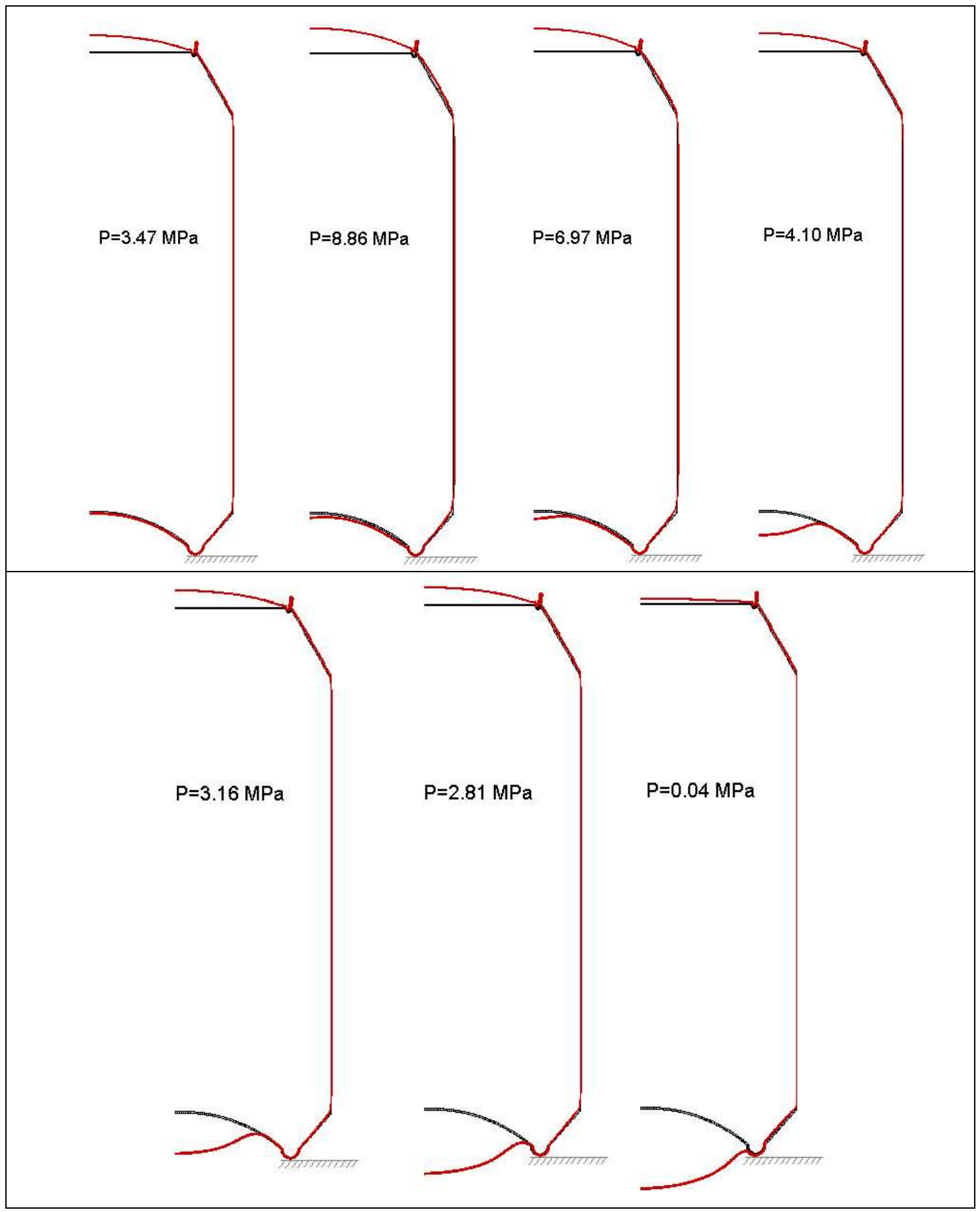

Figure 5 - Deformation evolution for the geometrically non-linear analysis without plasticity 


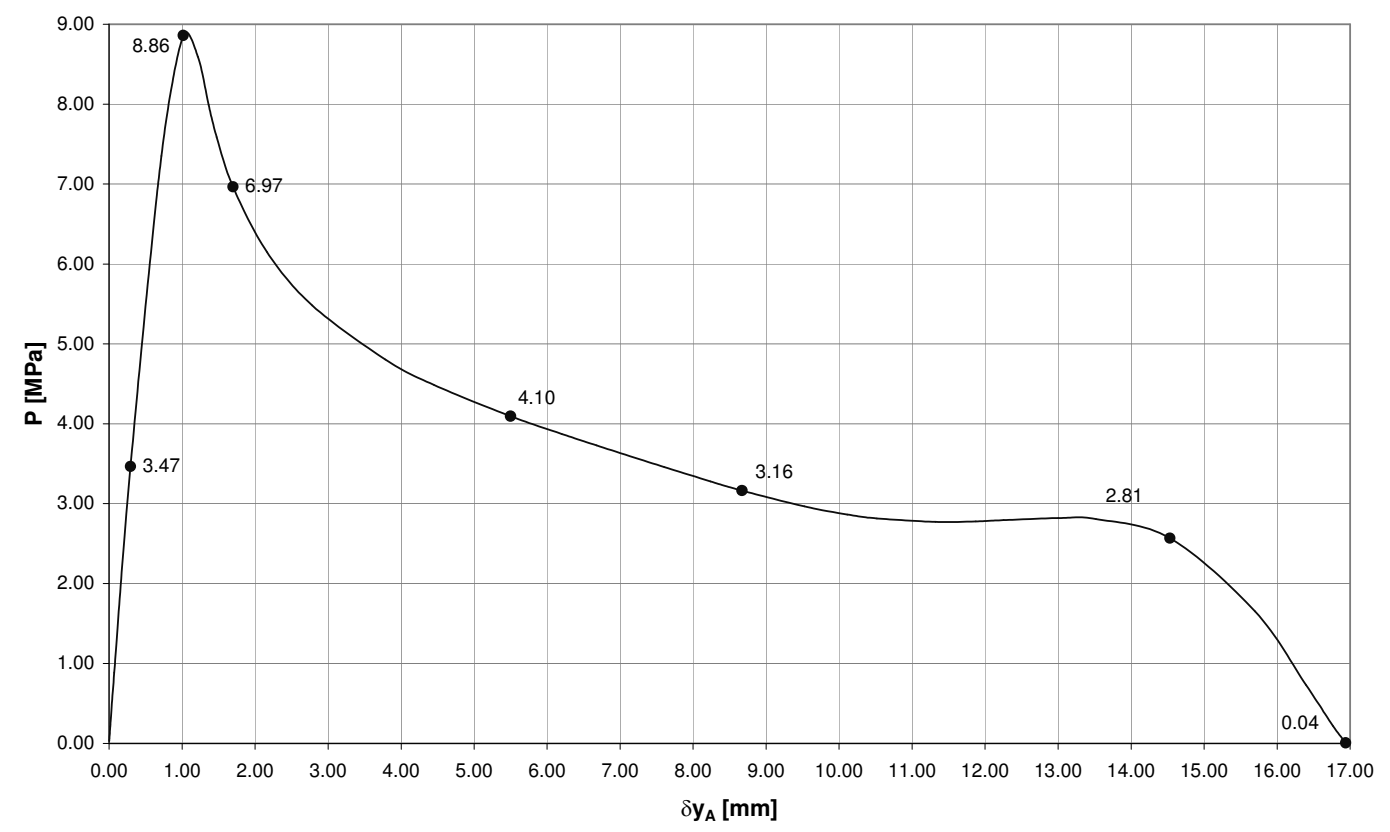

Figure 6 - Pressure - vertical displacement curve for point A at the base dome surface considering geometrical non-linearity only

\section{The fifth step - geometrically and materially non-linear analysis}

Finally large deformation and plasticity effects were combined together. The von Mises yield criterion ${ }^{10}$ was adopted for both materials, taking the yield stress values of Table 1 . The pressure - vertical displacement curve of Figure 7 shows a substantial decrease of the

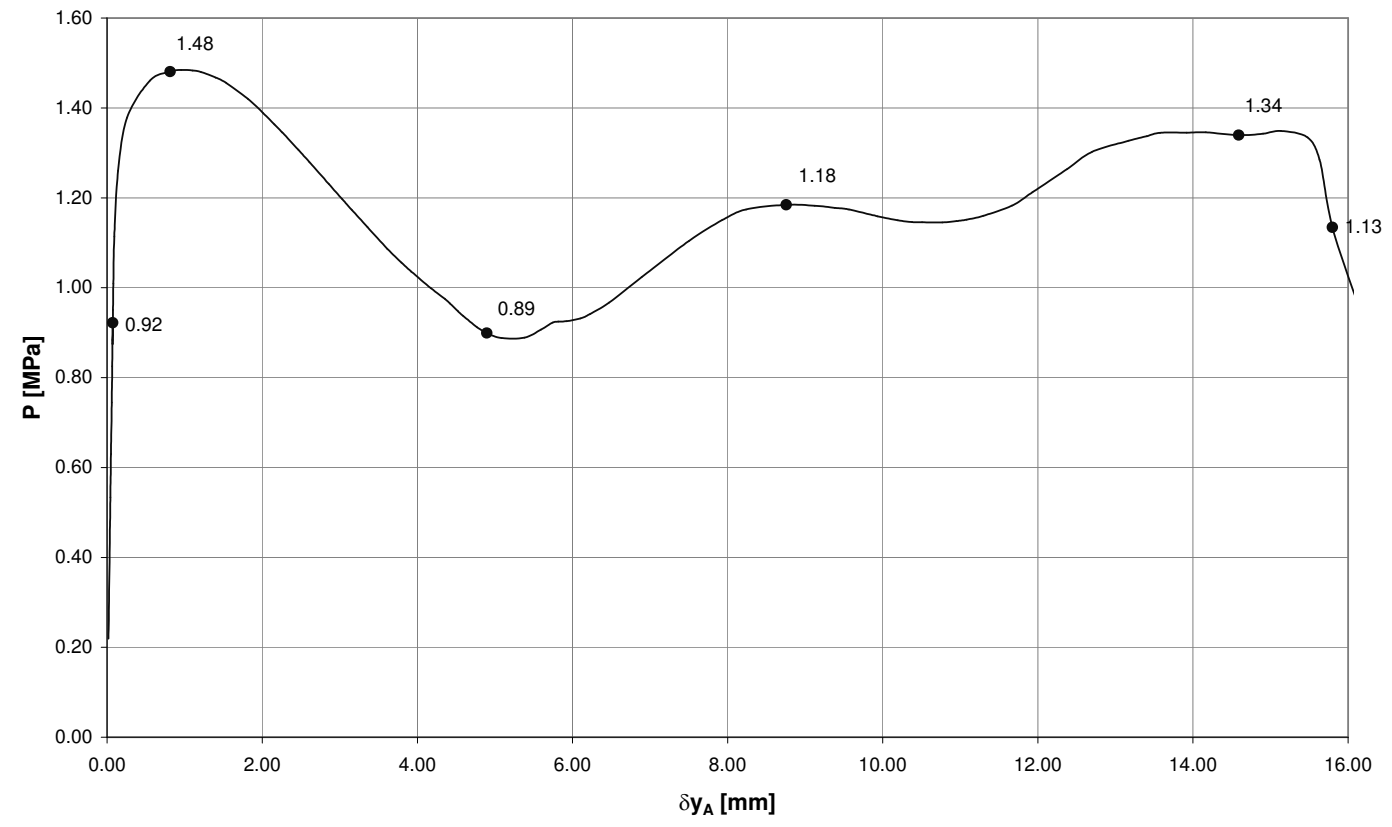

Figure 7 - Pressure-vertical displacement curve for point A at the base dome surface with combined material and geometrical non-linearity 
pressure required to trigger base dome reversal, which is now $1.48 \mathrm{MPa}(214.6 \mathrm{psi})$, in other words six times lower. The evolution of the can geometry can be followed in Figure 8.

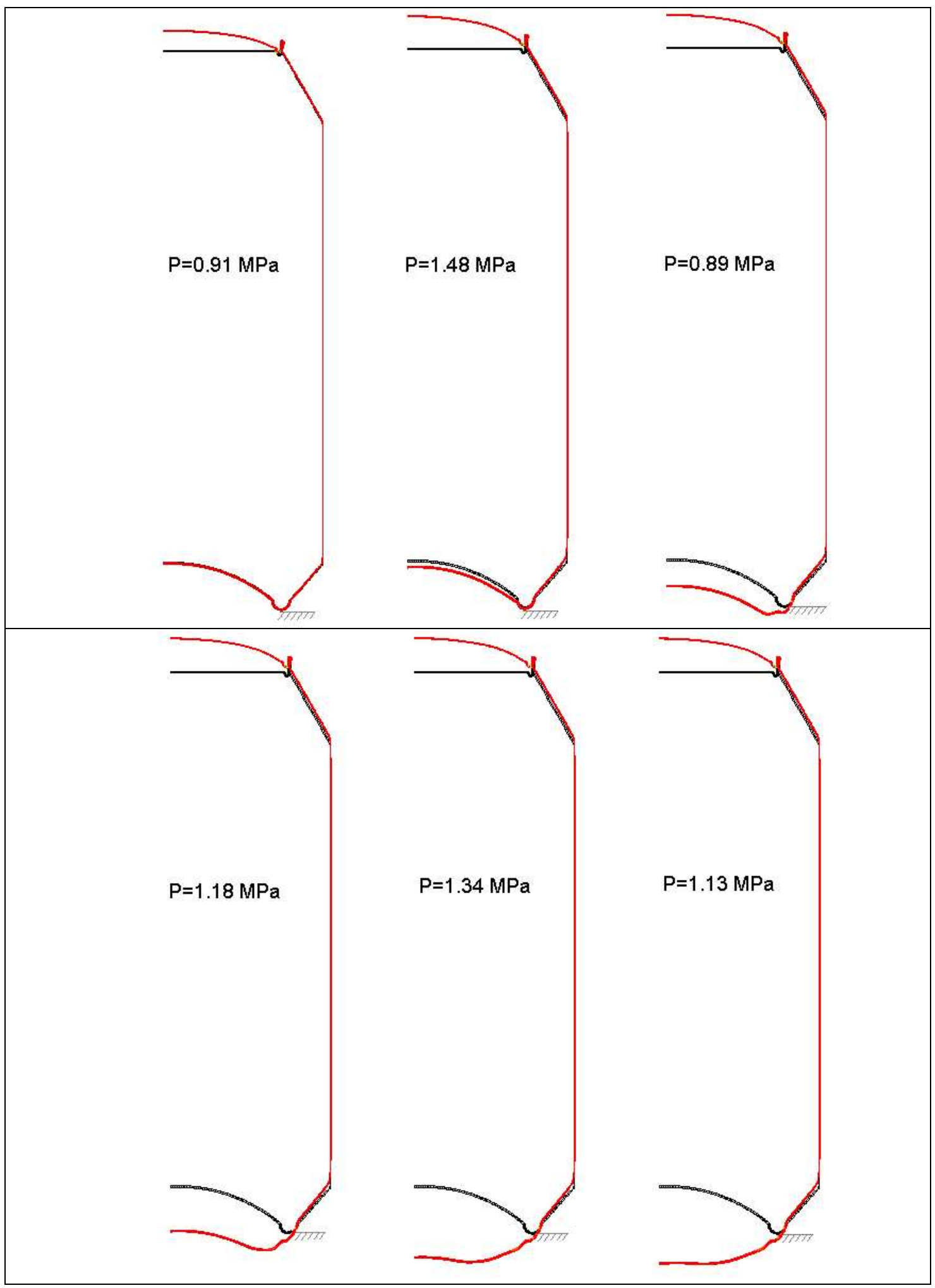

Figure 8 - Deformation evolution for the geometrically non-linear analysis with plasticity

Proceedings of the 2002 American Society for Engineering Education Annual Conference \& Exposition Copyright (C) 2002, American Society for Engineering Education 
The effective plastic strain plots of Figure 9 highlight the localized nature of the plastic hinges that develop in regions of the can lid and base with small curvature radii, which led to the much softer structural response registered in the geometrically and materially non-linear analysis, including a fuller base dome reversal.

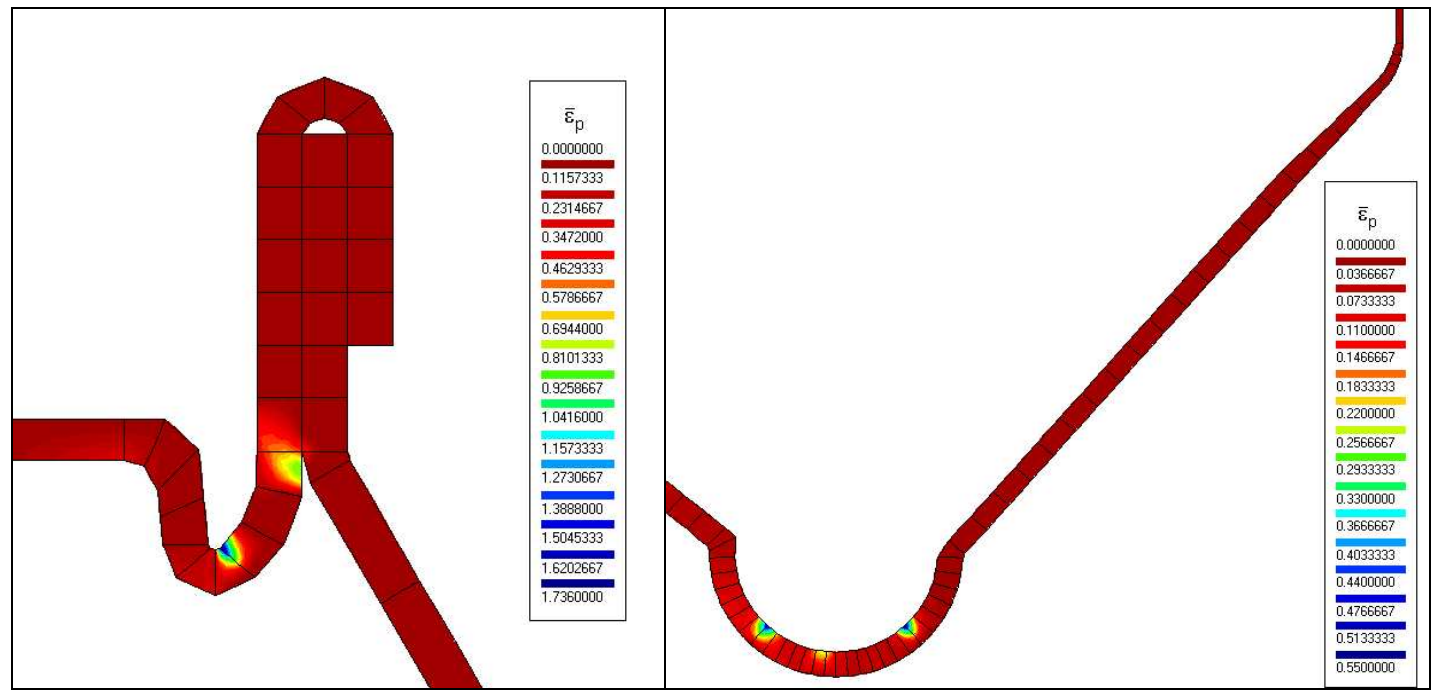

Figure 9 - Effective plastic strain field for the final stage of the geometrically non-linear analysis with plasticity, plotted on the initial undeformed mesh

\section{The final step - what else can be done?}

In an open-ended problem, as the one we have been discussing, it seems appropriate to briefly outline some avenues for further development. The question that needs answering is: how to gain a deeper insight into this simple problem?

As far as experimental measurements are concerned we intend to investigate two aspects in more detail.

The first one is the internal can pressure and its temperature dependence. One possible strategy, requiring some support from one soft drink company, will be to insert into the can, before the lid is seamed shut, wireless temperature and pressure sensors whose signals are recorded by external equipment. Slowly raising the can temperature in a thermostatic bath should provide an accurate pressure vs. temperature curve, as well as the answer to our second concern: the dome reversal pressure.

We should add that some steps have already been taken to analyse this phenomenon, with recourse to less sophisticated technology (see Figure 10).

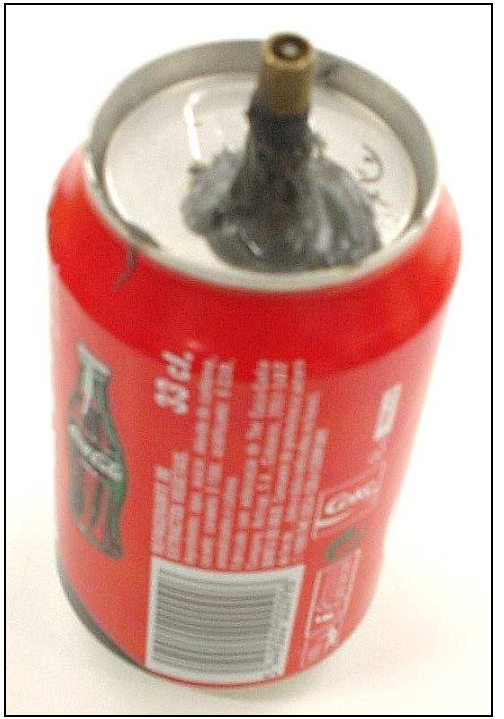

Figure 10 - Can prepared for dome reversal investigation 
The numerical simulation could be improved by using thin shell elements, by refining the lid seam modelling allowing for separation and by performing a fully three-dimensional analysis based on very precise geometrical and material data. In order to completely account for the material anisotropy induced by rolling in the flat metal sheet from which the can body is manufactured, the full forming process would have to be modelled.

\section{Closure - some food for thought}

In this case study topics from several engineering fields, such as metallurgy, instrumentation and measurements and computational mechanics, were combined and the capabilities of cooperative teaching and learning were exercised. As a result a very motivating problem was devised around a familiar object, in what proved to be an interesting opportunity for bringing together different domains of engineering that are usually treated independently from each other.

Teaching experiments of this kind are obviously not easy to carry out with large classes but they are extremely effective in potentiating the initiative and the imagination of the occasional, but always welcome, small group of proactive students. And besides, as an inspirational contribution to an educational engineering web site ${ }^{12}$, they are readily made available to a larger audience. In this particular problem the experimental results supplied the incentive for further exploration using numerical tools that ended up being much more wide ranging than initially planned, but this is one of the good points about open-ended problems: one finds the way as one goes along.

"If you always do what you have always done, you will always get what you have always got" ${ }^{11}$. This is the traditional, risk-avoiding, time-saving, way of teaching. Exploring multidisciplinary open-ended engineering problems as part of a cooperative learning strategy, requires careful planning, good coordination of manpower and resources, an open mind and the right mental attitude from all staff members involved. It promotes student teamwork skills and personal responsibility, as well as their self-organising and conflict-solving capabilities. It develops the students' capacity to analyse, interpret and criticise results, while integrating diverse fundamental concepts in a structured, operational way. And, last but not the least, it most often constitutes a rich learning experience for the teachers involved in such cooperative exercise.

We end by quoting student feedback (as conveyed by PP).

"At the start of this whole project, that prompted the active participation of my colleagues and I, we had to deal with the mechanical characterization of the can material, which required manufacturing a test specimen from the can body and devising an imaginative way of attaching this very thin specimen to the tensile testing machine. It taught us that mechanical material parameters are not always easy to determine. And that sometimes a little creativity has to be employed. The contacts with experts in mechanical testing, metal forming and machining were very helpful. They gave us a perspective of what can be done, how it can be done and how much it will cost.

We were then confronted with the problem of instrumenting a soft drink can with strain gauges. This may not seem a very big challenge but our previous experience was limited to preparing the flat surface of a solid aluminum bar for bending strain measurements. 
Finally came the question of setting up the acquisition system for reliably recording the data. Again our experience with the software had been based so far on "textbook" problems only, solved by merely following clear step-by-step instructions. We had to spend several hours exploring the software and carefully adjusting various parameters, such as the sampling rate and the measurement range based on our theoretical predictions.

We now know that real problems do not have exact solutions. And experimental results often cannot be accurately predicted. But we have learned that unexpected results are extremely useful because they force you to investigate deeper into the phenomenon in question. In addition to giving us a flavour of modern technology, material science and finite element analysis, this work also made us aware of the big gap between what is usually done in normal classroom or lab activities and real-life problem solving and scientific research.

There are two ways for acquiring knowledge: you can either learn on your own or be taught. This experience has showed us that the only thing one can efficiently teach is how to learn."

\section{Acknowledgements}

The third author wishes to thank his colleagues Miguel Sá Fernandes and Rui Ribeiro for help during the experimental stages of the work.

The support of Eng. Fernando Oliveira, Principal Research Officer, is gratefully acknowledged.

Bibliographic information

1. Automated System for Educational Training on Punching Process Characterization, Teresa Restivo and Joaquim Mendes, National Instruments User Solution (Education/Mechanical Engineering), Texas, 1998.

2. Experiential Learning - Experience as the Source of Learning and Development, D. A. Kolb, Prentice-Hall, New Jersey, 1984.

3. Strength of Materials, S. P. Timoshenko, $3^{\text {rd }}$ edition, D. Van Nostrand, Princeton, 1956.

4. The Real Thing, Experimental Stress Analysis NOTEBOOK, Issue 1, October 1985, Measurements Group, Inc., Raleigh, NC 27611.

5. The Real Thing Revisited, Experimental Stress Analysis NOTEBOOK, Issue 13, April 1990, Measurements Group, Inc., Raleigh, NC 27611.

6. The Real Thing Revisited (Again), Experimental Stress Analysis NOTEBOOK, Issue 25, April 1995, Measurements Group, Inc., Raleigh, NC 27611.

7. The Aluminium Beverage Can, W. F. Hosford and J. L. Duncan, Scientific American, Volume 271, Number 3, pages 34-39, September 1994.

8. The Finite Element Method, O. C. Zienkiewicz, $3^{\text {rd }}$ edition, McGraw-Hill, London, 1977.

9. Non-linear Finite Element Analysis of Solids and Structures, M. A. Crisfield, Volume 1, Wiley, 1991.

10. Finite Elements in Plasticity - Theory and Practice, D. R. J. Owen and E. Hinton, Pineridge Press, Swansea, 1980.

11. If you always do what you have always done, you will always get what you have always got, Bob Matthew and Pete Sayers, Learning How to Think Like an Engineer - Cognitive Apprenticeship, Second International Conference on Teaching Science for Technology at Tertiary Level, S. Törnkvist (Ed.), KTH Royal Institute of Technology, Stockholm, 1997.

12. http://www.fe.up.pt/ trestivo/im/welcome.htm 
Biographical information

\section{JOSÉ COUTO MARQUES}

$\mathrm{PhD}$ (Wales), MSc (Porto), Lic.Eng. (Porto)

Associate Professor, Departamento de Engenharia Civil, FEUP

jmarques@fe.up.pt

TERESA RESTIVO

Equiv. PhD (Porto), Lic.Física (Porto)

Principal Research Officer, Departamento de Engenharia Mecânica e Gestão Industrial, FEUP

trestivo@fe.up.pt

PEDRO PORTELA

Undergraduate Student, Departamento de Engenharia Mecânica e Gestão Industrial, FEUP

em98043@fe.up.pt

RICARDO TEIXEIRA

MSc (Porto), Lic.Eng. (Porto)

Postgraduate Student, Departamento de Engenharia Civil, FEUP

rntt@hotmail.com 